\title{
Towards a new, complexity science of learning and education
}

\author{
T. Jörg ${ }^{\mathrm{a}, \mathrm{b}}$, B. Davis ${ }^{\mathrm{c}}$, G. Nickmans ${ }^{\mathrm{a}, *}$ \\ a Centre for Research on Teaching and Training, University of Leuven, Dekenstraat 2, 3000 Leuven, Belgium \\ ${ }^{\mathrm{b}}$ IVLOS Institute of Education University of Utrecht, The Netherlands \\ ${ }^{\mathrm{c}}$ University of Alberta, Canada
}

\section{Executive summary}

The nature of the relationship between theory and practice has been subject for discussion for many years. Several participants in this ongoing discourse urge that theory should be able to guide and inform practice and should offer solutions for problems that arise in daily practice. This implies that science should incorporate a theory of change in order to deal with the many problems that arise in our everyday lives, certainly now we seem to find ourselves in a rapidly evolving, evermore complicated reality. In this position paper we argue that the field of learning and education is in a crisis and that the current paradigms in educational science are unable to adequately resolve the problems that are encountered in pedagogical practice. We believe that a profound understanding of pedagogical reality is necessary in order to have the ability to make recommendations for a transformation improvement - of this reality. Present paradigms in the field of education are based on physicalism or linearity thinking, they neglect the inherent complexity of educational reality and therefore are not able to develop an indepth understanding of this reality. To overcome this crisis in education, a first necessary step is to acknowledge the crisis and to recognize that an adequate theory of learning and education should take the complexity of reality into account. We argue that a theory of complexity needs to be developed, a new paradigm for education that can grasp the complex processes of learning. Characteristics of this complexivist frame are a focus on the transphenomenal resulting in a transdisciplinary and interdiscursive approach, an orientation towards self-organisation and potentiality instead of pre-specified ends and an incorporation of a theory of change. Such a complexity approach involves a rethinking of modes of inquiry, a new lexicon and assessment practices that are geared to the complexity paradigm.

\section{Learning and education in crisis}

Over the past few decades, commentators from a diversity of domains have offered sharp criticism of "educational practice". Teaching methods are criticized as poorly fitted to the dynamics of human cognition; curricula are described as out of step with the current times and inadequate representations of parent disciplines; school structures are said to have failed to adapt to the increased diversities of the populations they serve and the mounting dynamism of their contexts, etc. In brief, what educational systems claim to be up to and what they are actually doing appear to be two very different things.

\footnotetext{
* Corresponding author. Tel.: +31302534414.

E-mail addresses: a.g.d.jorg@ivlos.uu.nl (T. Jörg), goele.nickmans@ped.kuleuven.be (G. Nickmans).
} 


\subsection{Education}

The ongoing development and elaboration of technological possibilities, which are presenting themselves at an ever-accelerating pace, make the situation even worse. Technology and culture evolve so rapidly that humans can no longer confidently predict the conditions of existence more than a few years hence. Transformations in human possibility are so dramatic and proceed at such ever-increasing paces that the prominent futurist Kurzweil (2005) has predicted that by the end of this century, the non-biological portion of our intelligence will be trillions of times more powerful than unaided human intelligence. This forecast is defended with extensive and detailed explications of trends over recent decades and centuries, noting that technological and cultural evolutions are not linear (accumulative), but an exponential (self-amplifying) phenomenon. This is an immense problem for an educational system that, historically, has been premised on the faith in the possibility to anticipate what learners will need a few decades from now. And so, while Kurzweil's claim may have the ring of hyperbole, as educators, we cannot help but be troubled with how ill-prepared our formal institutions are in the face of the unimaginable possibilities that are already unfolding and emerging around us.

The idea that traditional schooling may be on the verge of becoming an anachronism (if it has not already become so) should prompt educators and educational researchers to rethink the question, "Why educate?" Original rationales for schooling, such as the need to keep youngsters off the labor market or the need for a general prepared populace able to fit into a narrow range of adult roles, are less and less appropriate to emergent reality. We are already forced to acknowledge that we simply cannot anticipate the type of competences that will define for example a "literate" or "numerate" citizen a few decades from now. Indeed, we cannot even know if contemporary notions of literacy and numeracy will make sense 20 years into the future.

\subsection{Learning}

The crisis concerning learning manifests itself by noticing that traditional ways of thinking on this complex topic have not been able to define learning adequately. According to St. Julien (2005), the current framework of learning theory is woefully inadequate. Van Geert (1994) stated openly that 'it is completely unclear what teaching and learning entail if conceived at the level of specific activities and processess'. Shotter (2005) states that 'we totally fail to acknowledge for what learning really involves in all it dynamic complexity'. The relevance of this is expressed eloquently by Lakoff (1987): 'Our ideas about what people can learn and should be learning, as well as what they should be doing with what they learn, depend on our concept of learning itself'. More recently, scholars from different fields of cognitive science, neuroscience and educational science agreed upon finding a new, more integrated framework for building a 'New Learning Science' (Jolles et al., 2005). Within this new framework, we may be able to rethink the concept of learning. Only then we may be able to use learning in a 'wholly new way' (to use Shotter's expression, 2005).

\subsection{Our position}

Although the criticism above may sound extremely alarming, it is argued in this position paper that the problems we are facing may not be about formal education per se, but about certain assumptions inscribed in educational traditions that have perhaps outlived their utility. Being aware of the double meaning of crisis in scientific revolutions, as put forward in Kuhn (1970), both as a state of art in the field of science and as a potential start for innovation, we may take the crisis of today as a full opportunity for a change: as a start of a turning point. Only then we may be able to un-learn the learned incapacities in the isolated disciplines (Wertsch, 1998; Van Benthem, 2002). Ultimately we may take up the challenge of 'inventing' a new science (e.g. Vygotsky, 1926/1997). What we need is 'a genuine revolution with new faces' (Van Benthem, 2002, p. 78; cf. Kuhn, 1970).

\section{Educational research and the crisis of educational practice}

In this section, we take a look at the nature of educational research, and the possibility of a new science to improve pedagogical practices. We argue that not only educational practice is faced with a problem but that the field of social science has been in crisis since long. It seems in a state of what Nicolaus Cusanus long ago has described as a state of 'learned ignorance' (Verene, 1993, p. 16), remaining blind for what learning may be, unable to recognize its complexity. 


\subsection{Blinding paradigms based on physicalism/linearity thinking}

Many theoretical frames that are operational in the field of educational research are adopted and adapted from other domains of inquiry, such as psychology, sociology, literary criticism, and cultural studies. All these theories in social sciences are characterised in terms of the 'calculable and predictable', born in the age of Enlightenment (Mainzer, 2004; Starobinski, 2003). That is, the theories were developed and adopted, in large part, through a desire of researchers in the social sciences to be seen as more scientific, in the sense of the physical sciences-and, in particular, of physics. This very physicalism is not innocent as Midgley has stated in her book on the myths of science we live by: "The Enlightenment notion of physical science was imperialistic from the outset" (Midgley, 2004, p. 23). Social sciences are a wrong copy of the natural sciences (Schnabel, 2002), as envisioned by social scientist. Actually it may be regarded as a wrong copy based on a wrong notion of the natural sciences itself (Bohm, 1996; Laughlin, 2005).

In this position paper it is argued that social sciences remain blind to what learning may be, unable to recognize the complexity of it (Lakoff, 1987; Luhmann \& Schorr, 2000; Van Geert, 1994). Social sciences have been in crisis for quite some time, in part because they are the captives of what Edgar Morin (2001) has called 'blinding paradigms', and in part because they are the victims of what Elkana (2000) has called 'Enlightenment fundamentalism'1 (i.e. a fundamentalism with positivistic, objectivistic, deterministic, individualistic, dualistic, and reductionistic characteristics). It is for these very same characteristics of 'normal science', that social sciences have developed the learned incapacity to reflect on the crisis. So, to escape the very crisis, with its old ideas and habits of thinking we need to go beyond the common fundamentalism.

\subsection{The role of theory for practice}

Very often, traditional educational theories are not well fitted to the particular, pragmatic concerns of educators. Most theories tend to be concerned with description, focusing much more on the characterisation of specific phenomena than on how one might go about affecting those phenomena. We refer to an example from formal mathematics education in North America: the use of behaviorist principles to redefine pedagogical practices and curricula in the 1950s; the shift toward structuralist curricula and formalist pedagogies in the late 1960s; similar transformations prompted by constructivist epistemologies in the 1980s and 1990s; the liberatory pedagogy movement oriented by critical theory and cultural studies that is now influencing what students learn and how teachers are expected to teach. A problem in virtually all these orienting frames is that they cannot be properly construed as theories of education-at least insofar as teaching is understood in terms of the project of prompting learners away from certain activities or attitudes and toward others. Rather, these frames are more oriented to enhanced understandings of the dynamics at work at various levels of organisation. While useful, such descriptive insights fall short of informing the practical responsibilities of educators.

\subsection{Lack of reflection on the complex reality of learning}

There are more than 50 different theories of learning in the field of educational research (e.g. Atherton, 2005). The presence of so many theories of learning may be interpreted as a kind of diversity that we may, or perhaps should, celebrate. But this fact can also be interpreted in a very different manner: as both demonstrating and hiding the complexities of learning. These are the complexities of a reality that are mostly taken for granted, leaving them unavailable for reflection (Bak, 1997; Peters, 2005). It can be stated that it is precisely because of this lack of reflection that there still is no clear theory and no clear thinking about educational practice. For example, the dominant view of constructivism as a theory does not enable us "to design down to how students learn" (Sergiovanni, 1996, p. 38). The role of theory as a theory for practice, therefore, is still unclear.

An important question when thinking about a theory for practice is 'what is reality of practice about?' What kind of limits - as well as unexpected potentialities - may reality show in practice? What sorts of complexities are masked by our assumptions? For example, the complexity of (the reality of) learning and "the processes of knowledge formation ... are not at all well understood" (Desforges, 2001, p. 33; emphasis added). It seems that we are allowing ourselves

${ }^{1}$ Cf. Enlightenment dualism, as an example of this, in Midgley (2001), p. 179; see also Flood (1999), on the Enlightenment and science. 
to move along without any adequate theory about these sorts of processes (Desforges, 2001; Maturana, 1978). The dominant model still seems to be the rationalistic model of education, with its emphasis on means-end thinking (Luhmann \& Schorr, 2000; Midgley, 2001; Morin, 2001; Verene, 1993), which, following Morin (2001) leads easily to a perverted system. Thinking along these lines makes clear why 'pedagogy can never be innocent' (Bruner, 1996, p. 21). The lack of theory and of an adequate view of practice might be described as indications of what may be called "a deprivation of our culture" (Midgley, 2001, p. 179).

\section{Acknowledging the complexity of educational reality}

As indicated in the previous paragraph, we argue that current theories in the field of education render the complexity of educational reality not only largely unreflective, but even difficult to perceive as sites of reflection. In this section we illustrate the complexity of the educational system and explain what complexity thinking means.

\subsection{Recognising education as a complex system}

A complex system is defined as any system comprising a large number of interacting components (agents, processes, etc.), whose aggregate activity is nonlinear (not derivable from the summations of the activity of individual components) and which is characterised by self-organisation (Rocha, 1999). It may not be clear that the phenomenon of formal education is well fitted to this definition. Consider, for example, a classroom where children are learning math under the guidance of a teacher, using a particular curriculum and workbook. There are many interacting components, but where is the non-linearity, where is the self-organisation? Everything in this class will appear pretty organized: by the curriculum, by the educational end terms, and so on. To be able to understand the complexity of this system, we first need to take the concept of complexity into account. Paradoxically, however, understanding requires simplification, so the issue that presents itself is how we might undertake to simplify in a manner that preserves a sufficient sense of the inherent complexity.

On this matter, it is instructive to first look to entrenched strategies for simplification within science in general and educational science in particular. In these contexts, the habit is to simplify by reducing the "spatial" components in terms of number and by reducing the temporal complexity by linearising the processes. The standard recipe, with which all researchers are familiar, is this: First, take a time span that is short enough to allow for unidirectional causality. Then, measure independent variables over independent subjects, and consider the subjects as representatives of an underlying category. Finally, consider all variation not co-varying with your independent variable as "interference or noise".

This approach has had some remarkable successes. Replacing it by something else - if that is what we are up to places a very heavy burden on those who wish to do so. However, paradoxically, the success of the simple-linear-systems model is in itself a consequence of one of the properties of complex systems.

To begin, many complex systems exhibit superposition. Superposition implies the simultaneity of apparently incompatible properties. The success of the linear approach is a good example of this property. A complex system is complex enough for it to display a number of simple linear properties. Feeding information about such linear properties back into the system (e.g. in the form of evidence-based program prescriptions in the context of intervention or teaching) can, at times, work quite well. However, the problem is that we do not really know, in such a case, why such programs work, or whether and in which way they might eventually exert adverse effects on other parts of the system (see for instance Kazdin \& Nock, 2003).

Secondly, complex systems construct and maintain a synthesis of substance and process. 'Substance' refers to the constant, identifiable components of the system. For instance, a psychologist dealing with knowledge in a person, or the knowledge a child acquires in a teaching context that can be described as a set of concepts inside the person, relatively stable and clearly defined entities. However, a deeper analysis of those entities often shows that they are in fact processes (we are referring to the growing literature on embodied, distributed cognition, based on principles of dynamic systems; see for instance Smith, 2005). In order to understand complex systems, we need to focus more strongly on the structure and form of the processes and on the structure of causality over time (epigenesis). However, the problem is that process models are considerably more complex than substance models (compare a model of the object concept from a "substance" point of view, i.e. seen as an entity in the person's mind, versus the process description advocated by Thelen and Smith (Smith, Thelen, Titzer, \& McLin, 1999). Hence, process models are much less likely 
to feature in applied settings such as in education, which require action and intervention and in which the "cognitive load" of the models and representations cannot be too high.

Third, complex systems are multi-layered and multi-scaled. For instance, in order to understand formal education, one needs to understand the tightly coupled links between individual, group, society and culture, which operate and function on distinguishable but connected time scales, for instance, the micro-genetic, ontogenetic, historical and evolutionary time scales.

Fourth, in a complex system, causality is often mutual and reciprocal.

Fifth, properties are often distributed over various components. This is the property most explicitly studied under the framework of situatedness, and distributed cognition.

Finally, in complex systems, self images do not function as moulds that automatically impose their form onto some inert mass. Self-images (scientific theories, ideologies, policy programs) function in the complex dynamics, and their causal roles and effects require a study of their own.

Let us try to summarize briefly and also necessarily incompletely, how the messages based on a theory work in complex systems. The assertion is that education is a complex system, with all the properties that are characteristic of a complex system, and that it is necessary for researchers, policy makers and educators to adapt their educational actions and decisions accordingly. A good way of illustrating how a message functions in complex systems is to invoke the - in itself not entirely uncontroversial - notion of 'the meme'. Memes are the mental or cultural counterpart of genes and refer to units of information (ideas, opinions, theories, etc.) that are transmitted from one person to another. Since message "transmission" is not really about transmission at all, but about re-construction by the person who "receives" the message, meme transmission is a process in which the memes or messages are not only multiplied, but also transformed, diluted, extended, and so forth. Memes are clearly involved in a struggle for limited resources, such as the time, attention and cognitive space of the receivers. For instance, scientific ideas - such as the notion that education is a complex dynamic system - are transmitted to other scientists and further developed or criticized by them. In some cases, the messages are appealing and simple enough to enter the public media and then become the topic of popular magazine articles and television programs. For instance, the current public interest in the brain as an explanation of human behavior is likely to be related to a combination of several factors. There is the simplicity of the message ("particular regions of the brain are responsible for particular abilities or behaviors"), the availability of powerful visual images (colored pictures of brains with bright colors indicating which part is doing the hard work), innovative and impressive technology (various types of brain scanners), the promise of tangible handles for intervention (drugs that eventually affect the brain regions at issue). For scientists, an additional advantage is the sheer endless possibilities for subjecting any known form of behavior, ability or psychological property to potential brain localization. The brain message has also invaded the discourse on education in the form of so-called 'brain-based education'.

\subsection{A portrait of complexity theory}

Complexity thinking might be characterised as concerned with the transphenomenal - that is, with how forms and events unfold from and are enfolded in other forms and events, potentially in a nonlinear way. For example, when a group of experienced teachers is asked "Where does a learner's understanding of multiplication come from?", the collective response will likely include references to biological structure (e.g., the genetic predispositions to make distinctions, notice patterns, and preserve small quantities), physical experiences (e.g., of collecting, ordering, sharing), formal elaborations in the early years (e.g., learning a counting system, combining numbers), introduction of ranges of applications and images for multiplication through the middle grades (see Davis and Simmt, in press for a discussion of a dozen distinct metaphors for multiplication that are invoked by teachers), and increasingly abstract interpretations through the senior grades. In other words, for teachers, the "simple" concept of multiplication is recognized as transphenomenal, involving genetic structure, bodily activity, social interaction, and cultural tools. In brief, multiplication is a complex concept.

Arguments over the relative worths of subject-centered constructivisms and social constructionisms make little sense here. Rather, the complexivist question is not "Which is (most) correct?" but "To which level(s) of complex emergence does a particular theory apply?" In this way, complexity thinkers are able to reconcile discourses as diverse - and seemingly opposed - as analytic science and post-structuralism. A vital element here has to do with the paces of evolution of the phenomena at hand. Analytic science has proven itself a powerful means to understand those phenomena that are relatively stable — that is, those that evolve on time scales of eons. However, analytic science has 
been almost useless for making sense of those phenomena that can transform themselves in years, days, or seconds, such as societal norms or personal understandings. Post-structuralism and related discourses, like Vygotsky's dialogical writing about his ambitious aim of building a new science based on the discovery of the complex dynamic essence of the given area of phenomena, have proven to be much more relevant here.

When looking back at the responses of the teachers, the list might seem problematical. How can such sweeps through and across phenomena make sense? Given the limitations on human perception, would not a domain with such broad, entwined interests be self-defeating? And, of particular relevance in this "postmodern era," is complexity thinking not simply an instance of one grand narrative deposing another while replacing entrenched sets of blind spots and injustices for others? These worries are, of course, legitimate. But thinking in terms of complexity does have a response. It is not a metadiscourse or metanarrative, but an umbrella notion that is organized around the human tendency to think associatively. It asks: How is a brain like (and not like) a city? How is an individual understanding like (and not like) a body of knowledge? These sorts of queries do not collapse phenomena into variations on a theme; rather they preserve the integrity of the phenomena under discussion, oriented by the recognition that such phenomena must be studied at the levels of their emergence.

Complexity theory is not interdisciplinary, but transdisciplinary (Van Benthem, 2002). This term is used to flag a research attitude in which it is understood that members of a research team arrive with different research agendas and different disciplinary backgrounds, yet are sufficiently informed about one another's perspectives and motivations to be able to work together as a collective. In a sense, contemporary educational research might be characterised as transdisciplinary. In the current literature, one regularly encounters studies framed by or located within neurology, psychology, sociology, or anthropology - to mention a handful of domains. However, on the level of individual reports, it is rare to come across a truly transdisciplinary study in which co-authors come from separate domains and where they grapple with the conflicting worries of their respective disciplines (Van Benthem, 2002).

Indeed, within the contemporary educational research literature, far from grappling with differences, there seems to be a tendency to accentuate divergences. For example, within the subject area of mathematics education, this tendency has been most pronounced in a seemingly endless debate around which is more correct, Piagetian-inspired subjectcentered constructivisms or Vygotskian-inspired social constructionisms. To the complexivist, such debates border on the inane. Piaget and Vygotsky were not at odds; they were merely looking at two distinct levels of complex emergence.

\section{Building a new science of learning and education}

Thinking in complexity may, or should, lead to a different science of learning and education, one that is characterised by acknowledging the complexity of reality, its non-linearity, and the important role of time in human functioning (Luhmann \& Schorr, 2000; Van Geert, 1994). It is a science of being through becoming, encompassing the role of time and complexity (Prigogine \& Stengers, 1984). For this new science, we need new "tools of thought," to go beyond our trained thinking in terms of linear causality (Prigogine \& Stengers, 1984, p. 203) as a lever to change science. We mean, here and now, in particular the science of education, "its epistemology - its world view" (Toffler, 1984). To build a new science of learning and education we must be aware that "linear thinking may be dangerous in a non-linear complex reality" (Mainzer, 2004, p. 407).

\subsection{Recognising the crisis of education}

Only when it is recognised that education is in a crisis, and when the causes of this crisis are recognised, will we be able to deal with the problems this crisis brings along. The importance of this sort of acknowledgment was also noted by Vygotsky in his first years as a scholar. He saw it as one of the preconditions for a paradigm shift in his field of study to formulate a so-called 'theory of the crisis' (see Vygotsky, 1926/1997, for his work on the crisis in psychology, which was not published until after his death). By describing and formulating such a theory in the field of education, we might be able to perceive a crisis, understand its effects, and start to 'solve' it.

Of course, this is not an easy job to do. It will never be the case that every scholar in the field will agree there is a crisis in the first place. Hence, in our view, the current situation is related to what Morin (2001) has called "the epistemological problem' in which "the crisis worsens as fast as the incapacity to reflect on the crisis increases" (Morin, 2001, p. 35). James Wertsch explained that a situation like this can emerge because of "the 'learned incapacities' and 'disciplinary pathologies' that restrict the horizons of modern academic discourse” (Wertsch, 1998, p. 11). 


\subsection{Escaping old habits and thoughts}

So, to actually change paradigm, we may need not only a theory of the crisis and a sense of the field as in a state of growing crisis (Kuhn, 1970), but also a better understanding of how to escape the crisis we are in. We must first become aware that we tend to take complexity of practice for granted. Only after recognizing this tendency will we be able to recognize the complexity of reality of education. To escape old ways of thinking, we need to face the complexities of educational practice by starting "to think in complexity" (Mainzer, 2004). Consequently we should develop new tools of thought, of thinking beyond dualism, reductionism, the calculable, and the strong wish of being in control of what happens in practice (Prigogine \& Stengers, 1984).

Doing so may lead to a very different view of reality. We take Darwin's complexification of the notion of reality as a source of inspiration. He was clearly able "to escape dear old habits of thought" (Dennett, 2003). Darwin's work showed that science itself is not an 'independent variable' and that we do not simply have to accept reality as we experience it (Alvin Toffler, in Prigogine \& Stengers, 1984). In line with this reasoning, Midgley states that "we need to stop treating 'science' as if it were a single monolithic entity" (Midgley, 2004, p. 22).

Maybe even more important is the fact that Darwin showed that the nature of the human, and humanity in general, had to be viewed (very) differently. This brings us to the 'ethical question', which can be viewed as fundamentally related to the new paradigm of complexity and complex systems, and the ethics of our sciences with their ethical consequences (Mainzer, 2004). Edgar Morin is clear in his expectations about the humanizing effect of taking complexity seriously: "complexifying, that is humanizing the sciences"2 (Morin, 2002, p. 9). The same is true for Klaus Mainzer, who argues convincingly to consider humans as complex nonlinear entities of mind and body (Mainzer, 2004 , p. 410). In his view, the ethical consequences "depend on our knowledge about complex nonlinear dynamics in nature and society" (Mainzer, 2004, p. 411; Van Benthem, 2002). They are, however, "not derived from the principles of complex systems" (Mainzer, 2004, p. 411). For us the challenge of such humanizing by complexifying is in making reality richer in all aspects (Morin, 2002b, p. 383). It may be regarded as a way to overcome the seemingly hidden "deprivation of our culture," hidden by the myths we live by (Midgley, 2004; Van Benthem, 2002).

So, we may conclude that we desperately need a theory of the crisis we are in, to be able to overcome the crisis, and to sketch the significant 'human benefits' for the field of education and all people involved in it. Here we are speaking of the benefits for the students in that field, who are strongly dependent on the view of practice and the organisation of educational practice in that very field of education. We acknowledge that this view is not innocent at all: The new kind of thinking in complexity and theorizing on the dynamics of complexity "points out that the way things unfold is inherently unknowable to the human mind, emerging through spontaneous self-organisation ..., rather than advanced planning" (Flood, 1999, p. 90; emphasis added).

\subsection{An new integrated set of paradigms}

What we need for a new science of learning and education, is an evolutionary paradigm for the social sciences, to be linked with the complexity paradigm (Morin, 2002b, see also Vygotsky's evolutionary point of view in Valsiner, 1998, and Van der Veer, 2000, p. 348). Such an integrated set of paradigms could enable to take a transdisciplinary approach to science (Koizumi, 2001; Morin, 1997; and the publications of CIRET, an international center for trans-disciplinary research in Paris). This approach would be founded on complexity theories with transdisciplinary tools of thought, and it would incorporate a theory of change. Such an approach could help to show us "the complex emerging from the simple" (Toffler, 1984, p. 29). The linking of evolution and complexity can be done by studying the evolution of complex systems, with their unexpected, counterintuitive responses of such systems, responses which are beyond control! (Prigogine \& Stengers, 1984).

This approach may lead to an expanded and expanding notion of reality: a panoramic vista of 'reinventing' reality of learning and education as a 'richer' version of reality (Morin, 2002b, p. 383; emphasis added). What we need for a science of education, according to Desforges (2001), is not only 'a blue skies' research agenda, of "research which thinks the unthinkable," (Blunkett, quoted in Desforges, 2001, p. 32), but also "researchers who can challenge

2 “complexifier, c'est humaniser les sciences". 
fundamental assumptions and orthodoxies and this may well have big policy effects further down the road" (Blunkett, quoted in Desforges, 2001, p. 32; emphasis added).

We may end with a generative science of education, which is similar to the generative biology of Webster and Goodwin (1996) and the 'generative Social Science' of Joshua Epstein (2006). The generative processes involved may imply so-called 'states of being' in the processes of becoming (Luhmann \& Schorr, 2000, p. 245). These states may become states of transformative 'nonlinear being' positively linked to a capacity required to adapt to a changing world (Stanley, 2005; Vygotsky, 1987).

\section{The value of this new paradigm for education}

\subsection{Understanding and transforming phenomena}

Complexity thinking is of particular relevance to projects of schooling. Prompted by its transdisciplinarity, two complementary emphases have arisen within complexity research. Complexity thinkers have contributed both to understandings of phenomena (i.e., to descriptions) and to a pragmatics of transformation. That is, by seeking to understand the qualities and conditions that are common to a tremendous range of forms and events, complexivists have begun to articulate explicit advice on how one might go about affecting the systems under study.

This advice is not presented in directive or causal terms, since complex unities are self-specifying (i.e., their responses might be dependent on particular perturbations, but are determined by their own embodied-historical structures). Cognizant of such structure determinism, many complexivists have focused their attentions on the conditions necessary for complex emergence. Extensive lists of necessary conditions have been assembled, and these include such elements as feedback loops, the possibility of dying, a means to preserve information, stability under perturbation, and reproductive instability - most of which are difficult to manipulate on the level of social interactivity. However, within the sorts of complex unities that concern educators and policy-makers, a few conditions can be tinkered with effectively. These include internal diversity, internal redundancy, decentralized agency and control, and neighbor interactions. It is beyond the purposes and means here to go into detail on these matters (see Davis \& Sumara, 2006, for an elaborated discussion), but the point is that it is possible to occasion the emergence of enhanced, transcendent capacities in individuals and social collectives. Indeed, this conclusion has been demonstrated in research laboratories, social institutions, and multinational companies around the world (Hutchins, 1995; Suroweicki, 2004). Formal education lags somewhat behind.

\subsection{Focusing on potential instead of ends}

The new complexity paradigm and its related thinking and theorizing implies a complexity that should be taken as a serious option for the practice of learning and education. This involves the abandonment of the desire to pre-determine outcomes. Rather than being framed in ends-oriented terms, education might become possibility-oriented. Learning, education, and the complexity of reality might be linked with very different options for the reality of learning and education: "... we should be realistic in a complex way, understanding the uncertainty of reality, knowing that the real holds invisible potential" (Morin, 2001, p. 70). This is how, in our view, reality in learning and education could be, and should be expanded into dynamic Vygotskian spaces of possibility and potentialities of learning and development for learners (Van Geert, 1994; Moll, 2000). The complex, tortuous paths of learning can be pictured as time-related learning trajectories in those multidimensional transitional spaces (Jörg, 2006). Pictures like this show how the world of processes (of learning) can be linked with the world of trajectories (Prigogine \& Stengers, 1984).

\subsection{Transdisciplinarity for a deeper understanding of phenomena}

Complexity thinking is not just transdisciplinary, but also interdiscursive. It compels attendance to the novel possibilities and emergent laws that arise at new levels of organisation, noting that discourses might be simultaneously appropriate to the phenomena at hand and incommensurate with one another. In this way, such disparate and mutually antagonistic domains as behaviorist psychology, critical pedagogy, and environmental ethics can be brought together in enhanced understandings of human possibilities. Doing so may lead to a humanizing of the sciences (Morin, 2002a). To re-emphasize, however, complexity thinking is not a unifying force. It is more a recognition that an interpretive richness might arise when diverse understandings are made to speak to (instead of against) one another. 


\section{The future of a new paradigm}

\subsection{Research in a linear relations frame versus a complexivist frame}

Science is invented, not found. A core tenet of complexity thinking is that modes of inquiry and strategies for interpretation are co-specified by - or, more colloquially, arise in conversation of - the observer and the phenomenon. The phenomenon plays a role in deciding how it might be studied.

In a similar sense, education and teaching are invented. They arise in particular circumstances, in response to particular needs and in anticipation of particular hopes. As well, they are organized around specific beliefs about how learning happens. We thus need to see how the complex processes involved in learning and education may work and how they might affect learners: "It is not likely that much progress will be made over time in improving schools unless we accept the reality that leadership for the schoolhouse should be different, and unless we begin to invent our own practice" (Sergiovanni, 1996, p. xiv; italics in original). If we want to elaborate a complexity approach, much effort must go to the empirical grounding of complexity and its related concepts and properties, i.e. the (reciprocal) dynamics of complexity and of its unexpected effects (see Van Geert, 1994, p. 195). The major problem is that research along the lines of the linear simplicity model is typically seen as easier to carry out and as leading to much more powerful and more generalizable results.

Of course, appearances can be misleading. Even the most statistically sound result cannot be generalized beyond the population studied; minor changes in circumstance can render a longstanding conclusion irrelevant; and impressive statistics can conceal almost irrelevant results. Consider an example: a highly significant $(p<0.01)$ correlation between externalizing problems and time spent in daycare (of for instance 0.1) found over thousands of subjects, seems a very impressive finding. However, it means that daycare and externalizing problems have $1 \%$ of their variance in common, which is a magnitude that the naked eye cannot see. (This example refers to the discussion that originated on the basis of the NICHD research project on the effect of daycare; see for instance Belsky, 2002.)

In contrast to statistics-based studies that can be carried out relatively easily - on many participants at once, using techniques like questionnaires or computerized tests - research into the dynamics of complex systems requires mostly intensive, long-term, fine-grained, and often-tedious examinations of agents and processes, usually with high-frequency repeated measures or observations. The only way to obtain insight into the dynamics of those processes is to actually study them, i.e. their performance in practice, and this will proceed in a piecemeal fashion. For some phenomena, many individual or small sample studies are needed before a critical mass of data is achieved, given the many and varied ways that agents in a system might affect one another. Another problem with these usually very intensive studies is that they are considerably more difficult to carry out than probe-oriented studies (in which, for example, subjects fill in a questionnaire). A further complicating issue is that, the researcher must almost become part of that process itself (see for instance Van Geert \& Steenbeek, 2005 for an example). In a linear frame, such participation is seen as confounding and researchers are urged to avoid it; in a complexity frame, particularly in studies of social systems, it is understood as inevitable - and, therefore, a necessary element of the inquiry.

\subsection{Lexicon of complexity}

It seems that we need a new transdisciplinary lexicon of complexity, with a lexical group of concepts such as '(causal) reciprocal interaction,' 'interactivity,' 'connectivity,' and 'generativity'. More fundamentally perhaps, the lexicon must include 'complexity' itself, with all of its inherent nonlinear dynamics and their potential nonlinear effects, including 'bootstrapping', 'multiplier effects', and 'deviation-amplifying effects'. All of these may be the result of reciprocal causation in peer-to-peer interaction (Maruyama, 1963). Also of relevance, given the pragmatic concerns of education, are understandings of 'causality'. On this count, we might 'simply' expand these notions of reciprocal causation to triadic reciprocal causation (Bandura, 1997), or even to web-like structures of causal reciprocal relations (Edelman, 2004; Hofstadter, 1979; Jörg, 1994, 1998, 2006a, 2006b, 2007a, 2007b, in preparation, on 'augmented transition networks'). More radically, Juarrero (1999) proposes significant reconfigurations of contemporary meaning of 'cause' to include both bottom-up and emergent top-down structures. With such emphases, we may really be able to re-invent the description and explanation of common reality of learning and education into a new, richer reality (Jörg, 2004a, 2004b, 2007a, 2007b, in preparation; Morin, 2001). 


\subsection{Emerging possibility instead of pre-specified ends}

Policy-makers might consider entrusting other constituencies - schools, teacher groups, classroom collectives, and individuals - with some meaningful decision-making responsibilities and with opportunities to specialize. To explain, it is in the specialization of interacting agents that biological bodies, social collectives, institutions, and corporations become "intelligent," capable of more expansive possibilities within ever-shifting contexts. In (sometimes stunning) contrast, contemporary schools tend to minimize the possibility of learner or classroom specialization, opting instead for a sort of generic preparation and thereby militating against the emergence of more expansive collective possibilities. Of course, such discussions push us into the realms of morality and ethics. Which specialisations? Who decides? Whose interests? Whose conceptions of "intelligent" or "better" or "expansive"? These are not easy questions, nor are they ones with definitive responses. In fact, complexity thinkers themselves have highlighted these issues (e.g., Cohen \& Stewart, 1994; Varela, 1999) and, in the process, have foregrounded researchers' and educators' inevitable complicity in phenomena under study. Such complicity, it is argued, should compel attitudes of mindful participation. The point is not that we must fully anticipate the implications of our actions, but that we must be responsible for and responsive to their consequences.

\section{Conclusion}

If we are able to take the steps mentioned above, a new science that is rich with possibilities may emerge for the scholars in the fields concerned, particularly in the field of education. In our view the complexity paradigm should help to uncover some of the myths we live by, with their common metaphors and rhetoric. The suggestion here is not that a complexity paradigm might somehow provide access to an ultimate truth; it is, rather, that such a paradigm seems to be better fitted to our rapidly evolving, ever-more-complicated times. And so the hope is that it might enable us to be more aware of the myths that lead to the 'deprivation of our culture', (Midgley, 2001, p. 179) and to a perverted system of education - with its blind focus on ends (see Morin, 2001, p. 72); a system without a clear notion of the complex processes of learning; a system that negates that "learning is navigation on a sea of uncertainties dotted with islets of certainties" (Morin, 2001, p. 71).

\section{References}

Atherton J. S. (2005). Learning and teaching: Theories of learning. Available: http://www.learningandteaching.info/learning/theories.htm.

Bak, P. (1997). How nature works. The science of self-organized criticality. Oxford: Oxford University Press.

Bandura, A. (1997). Self-efficacy: The exercise of control. New York: W.H. Freeman.

Belsky, J. (2002). Quantity counts: Amount of child care and children's socioemotional development. Journal of Developmental \& Behavioral Pediatrics, 23, 167-170.

Bohm, D. (1996). On creativity. London: Routledge.

Bruner, J. (1996). The culture of education. Cambridge, MA: Harvard University Press. CIRET-Centre. Available at: http://nicol.club.fr/ ciret/english/visionen.htm

Cohen, J., \& Stewart, I. (1994). The collapse of chaos: Discovering simplicity in a complex world. New York: Penguin Books.

Davis, B., \& Simmt, E. (in press). Mathematics-for-teaching: An ongoing investigation of the mathematics that teachers (need to) know. Educational Studies in Mathematics, 61(3), 293-319.

Davis, B., \& Sumara, D. (2006). Complexity and education: Inquiries into learning, teaching, and research. Mahwah, NJ: Lawrence Erlbaum.

Dennett, D. C. (2003). Freedom evolves. New York: Viking.

Desforges, Ch. (2001). Educational research and educational practice. 'What does educational research have to offer to education?'. In A. Wald \& H. Leenders (Eds.), Wat heeft onderwijs-onderzoek het onderwijs te bieden? Den Haag: NWO.

Edelman, G. (2004). Wider than the sky. A revolutionary view of consciousness. London: Penguin Books.

Elkana, Y. (2000). Rethinking - not Unthinking - the Enlightenment. In W. Krull (Ed.), Debates on issues of our common future. Weilerswist: Velbruck Wissenschaft. Also available at http://www.ceu.hu/yehuda_rethinking_enlightnment.pdf

Flood, R. L. (1999). Rethinking the Fifth Discipline. Learning within the unknowable. London: Routledge.

Hofstadter, D. (1979). Gödel, Escher, Bach. New York: Basic Books.

Hutchins, E. (1995). Cognition the wild. Cambridge, MA: The MIT Press.

Jolles, J., de Groot, R., van Benthem, J., Dekkers, H., de Glopper, C., Uijlings, H., \& Wolff-Albers, A. (2005). Leer het Brein Kennen (Understanding the Brain). Den Haag: NWO.

Jörg, T. (1994). De keuze van het vak natuurkunde als examenvak en de wijze waarop die tot stand komt bij leerlingen in het MAVO en HAVO. Dissertation with a summary in English. 
Jörg, T. (1998). The development of a complex dynamic causal model for cyclically organized processes of cumulative advantage and disadvantage in education. In Paper presented at the annual meeting of the American Educational Research Association (AERA).

Jörg, T. (2004a). A theory of reciprocal learning in dyads. Cognitive Systems, 6-2(3), 159-170.

Jörg, T. (2004b). Complexity theory and the reinvention of reality of education. In B. Davis, R. Luce-Kapler, \& R. Upitis (Eds.), Proceedings of the 2004 complexity science and educational research conference. Available at http://www.complexityandeducation.ca

Jörg, T. (2006a). Minds in evolution through human interaction. Cognitive Systems, 6(4), 363-386.

Jörg, T. (2006b). Towards a new learning science for the reinvention of education-A trans-disciplinary perspective. In Educational research, policy and practice in an era of globalization. Hong Kong: The Asia-Pacific Educational Research Association., 92 pp.

Jörg, T. (2007a). Visiting the future of learning and education from a complexity perspective. In Chr. Stary, F. Barachini, \& S. Hawamdeh (Eds.), Knowledge management: Innovation, technology and cultures (pp. 227-241). New Jersey: WorldScientific.

Jörg, T. (2007b). New thinking in complexity for the science of education-A trans-disciplinary approach. In Proposal for presentation at the SIG chaos and complexity theories at AERA 2008.

Jörg, T. (in preparation). New thinking in complexity for the social sciences. A trans-disciplinary approach.

Juarrero, A. (1999). Dynamics in action: Intentional behavior as a complex system. Cambridge, MA: The MIT Press.

Kazdin, A. E., \& Nock, M. K. (2003). Delineating mechanisms of change in child and adolescent therapy: Methodological issues and research recommendations. Journal of Child Psychology and Psychiatry and Allied Disciplines, 44, 1116-1129.

Koizumi, H. (2001). Trans-disciplinarity. Neuroendrocrinology Letters, 22, 219-221.

Kuhn, T. S. (1970). The structure of scientific revolutions (2nd ed.). Chicago: Chicago University Press.

Kurzweil, R. (2005). The singularity is near: When humans transcend biology. New York: Viking.

Lakoff, G. (1987). Women, fire, and dangerous things. Chicago: University of Chicago Press.

Laughlin, R. B. (2005). A different universe. Reinventing physics from the bottom down. New York: Basic Books.

Luhmann, N., \& Schorr, K. -E. (2000). Problems of reflection in the system of education. European Studies in Education. 13. Münster: Waxmann.

Mainzer, K. (2004). Thinking in complexity. The computational dynamics of matter, mind, and mankind. Berlin: Springer.

Maturana, H. R. (1978). Biology of language: The epistemology of reality. In G. A. Miller \& E. Lenneberg (Eds.), Psychology and biology of language and thought. Essays in honor of Eric Lenneberg (pp. 27-63). New York: Academic Press.

Maruyama, M. (1963). The second cybernetics: Deviation amplifying mutual causal processes. American Scientist, 51, $164-179$.

Midgley, M. (2001). Science and poetry. London: Routledge.

Midgley, M. (2004). The myths we live by. London: Routledge.

Moll, L. C. (2000). Through the mediation of others: Vygotskian research on teaching. In V. Richardson (Ed.), Handbook of research on teaching (4th ed., pp. 11-129). Washington, DC: AERA.

Morin, E. (1997). Reformé de pensée, transdisciplinarité, réforme de l'université. Available at: http://nicol.club.fr/ciret/bulletin/b12/b12c1.htm.

Morin, E. (2001). Seven complex lessons in education for the future. Paris: UNESCO Publishing.

Morin, E. (2002a). A propos de la complexité. Available at: http://www.litt-and-co.org/philosophie/philo.textes.htm.

Morin, E. (2002). From the concept of system to the paradigm of complexity. Journal of Social and Evolutionary Systems, 15, 371385.

Peters, M. (2005). Editorial: New approaches in the philosophy of learning. Educational Philosophy and Theory, 37, 627-631.

Prigogine, I., \& Stengers, I. (1984). Order out of chaos. Man's new dialogue with nature. Glasgow: Fontana Paperbacks.

Rocha, L. M. (1999). Complex systems modeling: Using metaphors from nature in simulation and scientific models. [On-line]. Available: http://informatics.indiana.edu/rocha/complex/csm.html.

Sergiovanni, Th. J. (1996). Leadership for the schoolhouse. San Francisco: Jossey-Bass.

Shotter, J. (2005). Bringing corporeal life back in chiasmic relations and poetic understanding. In W. E. Doll, M. J. Fleener, D. Trueit, \& J. St. Julien (Eds.), Chaos, complexity, curriculum, and culture. A conversation (pp. 101-116). New York: Peter Lang.

Smith, L. B. (2005). Cognition, as a dynamic system: Principles from embodiment. Developmental Review, 25, $278-298$.

Smith, L. B., Thelen, E., Titzer, R., \& McLin, D. (1999). Knowing in the context of acting: The task dynamics of the A-not-B error. Psychological Review, 106, 235-260.

Stanleyu, D. (2005). Paradigmatic complexity: Emerging ideas and historical views of the complexity sciences. In W. E. Doll, M. J. Fleener, D. Trueit, \& J. St. Julien (Eds.), Chaos, complexity, curriculum, and culture. A conversation (pp. 101-116). New York: Peter Lang.

Starobinski, J. (2003). Action and reaction. The life and adventures of a couple. New York: Zone Booksoks.

St. Julien, J. (2005). Complexity: Developing a more useful analytic for education. In W. E. Doll, M. J. Fleener, D. Trueit, \& J. St. Julien (Eds.), Chaos, complexity, curriculum, and culture. A conversation (pp. 101-116). New York: Peter Lang.

Suroweicki, J. (2004). The wisdom of crowds: Why the many are stronger than the few and how collective wisdom shapes business, economies, societies, and nations. New York: Doubleday.

Toffler, A. (1984). Science and change. Foreword. In I. Prigogine \& I. Stengers (Eds.), Order out of chaos. Man's new dialogue with nature (pp. xi-xxxi). Glasgow: Fontana Paperbacks.

Valsiner, J. (1998). The guided mind. Cambridge, MA: Harvard University Press.

Van Benthem, J. (2002). Science and society in flux. In P. Tindemans, A. Verrijn-Stuart, \& R. Visser (Eds.), The future of sciences and humanities (pp. 63-90). Amsterdam: Amsterdam University Press.

Van Dijk, M., \& van Geert, P. (2005). Disentangling behavior in early child development: Interpretability of early child language and its effect on utterance length measures. Infant Behavior and Development, 28, 99-117.

Van Geert, P. (1994). Dynamic systems of development. Change between complexity and chaos. New York: Harvester Wheatsheaf.

Van Geert, P., \& Steenbeek, H. (2005). The dynamics of scaffolding. New Ideas in Psychology, 23, 115-128.

Varela, F. (1999). Ethical know-how: Action, wisdom, and cognition. Stanford, CA: Stanford University Press. 
Verene, D. P. H. (1993). Introduction: On humanistic education. In G. Vico (Ed.), On humanistic education (pp. 1-30). Ithaca: Cornell University Press.

Vygotsky, L. (1987). In R. W. Rieber \& A. S. Carton (Eds.), Collected works, Vol. 1. Problems of general psychology. New York: Plenum Press.

Vygotsky, L. (1997). R. W. Rieber \& A. S. Wollock (Eds.), Collected works, Vol. 3. Problems of the theory and history of psychology. New York: Plenum Press.

Webster, G., \& Goodwin, B. (1996). Form and transformation. Generative and relational principles in biology. Cambridge, UK: Cambridge University Press.

Wertsch, J. V. (1998). Mind as action. New York: Oxford University Press.

Wolstenholme, E. (2004). Using generic system archetypes to support thinking and modelling. System Dynamics Review, 20, 341-356. 